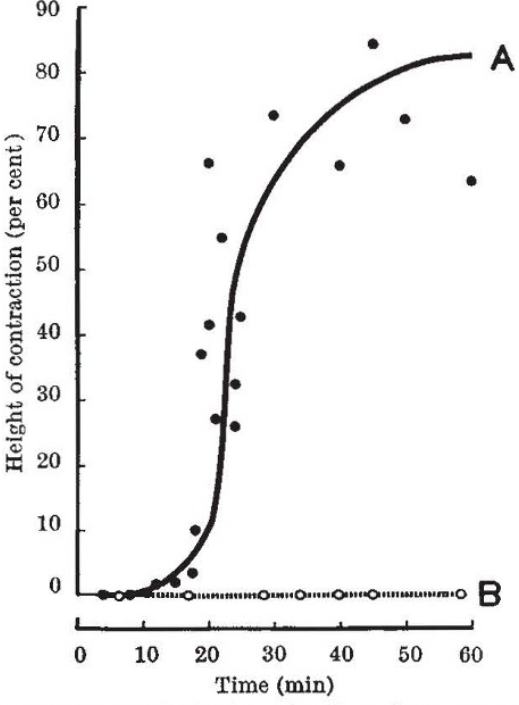

Fig. 2. Motor response of rat uterus to adrenaline under the influence of isoprenaline. $A$, Animals treated with stilboestrol; $B$, animals ovariectomized and treated with progesterone. Ordinate, height of contraction produced by adrenaline as a percentage of the height of the original intrinsic contraction; abscissa, time in minutes after onset of isoprenaline inhibition. Each point represents a result obtained with one horn of a uterus.

rat uterus in animals treated with stilboestrol, and not in animals treated with progesterone.

According to the receptor hypothesis, these results mean that $\alpha$ receptors are present in the rat uterus in animals treated with stilboestrol, but are absent or masked in animals treated with progesterone. If the $\alpha$ receptors are anatomical entities, it seems very improbable that they could appear and disappear in this manner; if receptors are closely related to enzymes, however, then treatment with stilboestrol for $40 \mathrm{~h}$ would afford sufficient time for such an enzyme to be induced. In this case the enzyme would probably not be induced in the presence of progesterone.

The form of curve $A$ in Fig. 2 may be explained by postulating that a substance with motor activity accumulates in the uterus during the period of isoprenaline inhibition, and is liberated by the addition of adrenaline; the amount liberated, and therefore the height of contraction, would be related to the time of addition of adrenaline during isoprenaline contact.

Department of Pharmacology,

AnNe TothilL

Guy's Hospital Medical School,

London, S.E.1.

' Butterworth, K. R., Brit. J. Pharm. Chemother., 21, 378 (1963).

\section{Islet Formation in the Cortex of the Human Thymus}

MoRPHOLOGIC units consisting of a central macrophagelike cell surrounded by several lymphocytic or plasma cells, and termed islets, are seen in lymph nodes ${ }^{1}$, and in cultures of lymph node cells ${ }^{2}$, blood lymphocytes ${ }^{3,4}$ and thymic cells ${ }^{5}$. Islets formed by lymphocytes and (or) eosinophilic and neutrophilic leucocytes are observed surrounding degenerating mononuclear cells containing antigens ${ }^{6}$.

It is the purpose of this paper to emphasize that a phenomenon similar to islet formation is frequently seen in the cortex of thymuses obtained at autopsies of infants and young children. In such thymuses, there is an obvious, though not very marked, destruction of cells in the thymic cortex. Pycnotic cells and small haematoxylin-positive particles of chromatin are seen scattered in the cortex.

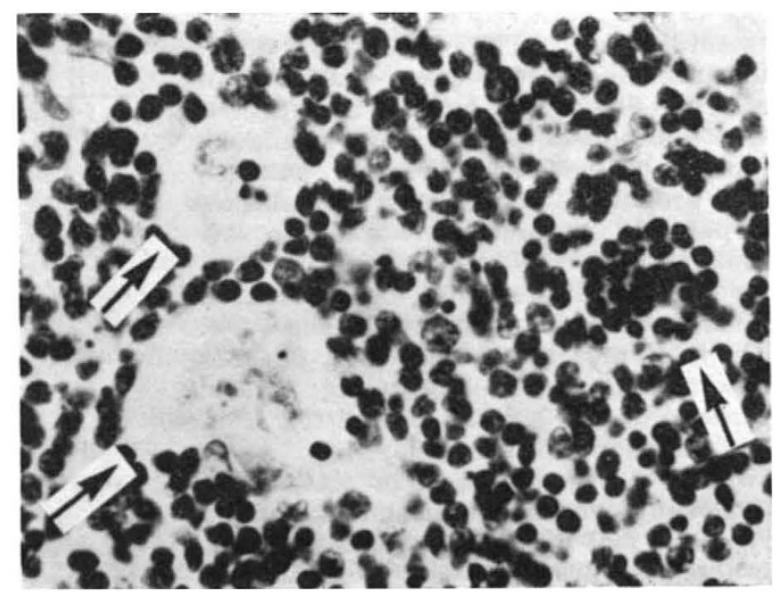

Fig. 1. Islets in different phases of development in the cortex of a human thymus. Haematoxylin and eosin section, $\times 160$. On the right is an islet formed by several deeply stained small and medium-sized lymphocytes. On the left are two islets in an early stage of development. In the upper islet there is a large cell with a paie nucleus and abundant cytopiasm particles. The lower islet shows lymphocytes just beginning to invade the islet.

Besides these there are, in most of the cases, peculiar oval areas containing homogenous masses of dead cells and often a large cell with a large pale nucleus and abundant cytoplasm (Fig. 1). These areas are infiltrated by lymphocytes resulting in the formation of islets (Fig. 1). The number of the cells in these islets varies greatly. Morphologically, the cells invading the islets are similar to small and medium-sized lymphocytes (thymocytes). Occasionally these cells stain with haematoxylin more intensely than the other lymphocytes. Some islets seem to be demarcated from the surrounding tissue by a thin membrane.

The hypothesis that RNA (ref. 7), breakdown products of DNA or other agents mediating information are obtained by the lymphocytes in the area of islets seems attractive, but definite evidence for such a theory is lacking. It is possible, at least in the thymus, that the Iymphocytes which infiltrate the islets are destroyed; the unknown fate of thymic lymphocytes under stress conditions might so be explained. Whatever the significance of the islets is, the observations presented seem to indicate that the thymus is not principally different from the other lymphoid organs in the capacity to form islets.

This investigation was supported in part by grants from the U.S. Public Health Service.

Kauko Kouvalainen

Children's Hospital, University of Helsinki,

Helsinki, Finland, and

Children's Hospital, University of Pittsburgh,

School of Medicine,

Pittsburgh, Pennsylvania.

1 Thiery, J. P., in Symposium on Cellular Aspects of Immunity, Boston (1960). 2 Sharp, J. A., and Burwell, R. G., Nature, 188, 475 (1960).

3 Barbefeld, H., and Juliar, J., Lancet, ii, 7363 (1964).

- McFarland, W., and Heilman. D. H., Nature, 205, 887 (1965)

${ }^{5}$ Sharp, J. A., Nature, 209, 828 (1966).

6 Spiers, R. S., and Spiers, E. E., J. Immunol., 90, 561 (1963)

${ }^{7}$ Fishman, M., J. Exp. Med., 117, 837 (1961).

\section{Mechanisms of the Crayfish Tail Flick}

THE escape reaction of the crayfish consists of a rapid backward swimming movement brought about by powerful flexion of the abdomen. In the course of a primarily anatomical re-investigation (as yet unpublished) of the musculature responsible for this flexion in the crayfish Procambarus clarki, it was observed that some 40 per cent of the cross-sectional area of the main flexor musculature is contributed by three muscles which both arise and 